
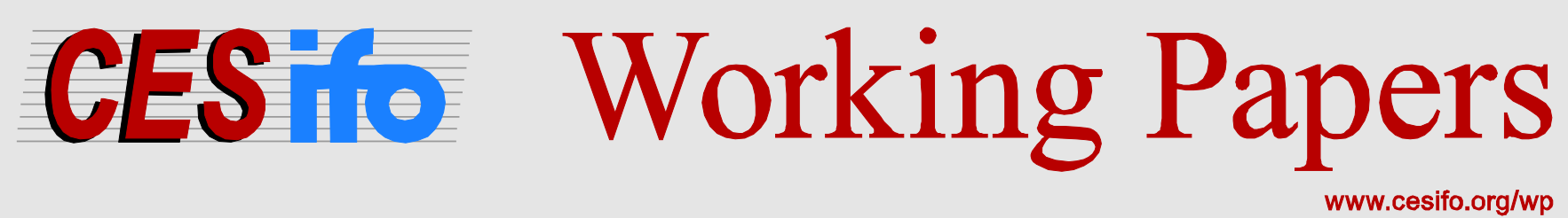

\title{
Is there a Friday the 13th Effect in Emerging Asian Stock Markets?
}

\author{
Benjamin R. Auer \\ Horst Rottmann
}

\author{
CESIFO WORKING PAPER NO. 4409 \\ CATEGORY 7: MONETARy POLICY AND INTERNATIONAL FINANCE \\ SEPTEMBER 2013
}

An electronic version of the paper may be downloaded

- from the SSRN website:

- from the RePEc website:

- from the CESifo website:

wWW.SSRN.com

Www.RePEc.org

www.CESifo-group.org/wp

\section{CESifo}




\title{
Is there a Friday the 13th Effect in Emerging Asian Stock Markets?
}

\begin{abstract}
In this article, we revisit the Friday the 13th effect discussed by Kolb and Rodriguez (1987) that has received increased interest in recent research. Using a dummy-augmented GARCH model, we investigate whether the occurrence of this superstitious calendar day has significant impact on the conditional means and variances of returns in the seven emerging Asian stock markets India, Indonesia, Malaysia, the Philippines, South Korea, Taiwan and Thailand. Results obtained for the period from July 1996 to August 2013 indicate no systematic pattern across countries. We can detect a significant Friday the 13th effect only for mean returns in the Philippines and an inverse Friday the 13th effect for South Korea. Volatilities are significantly affected only in Indonesia and the Philippines. They tend to be reduced by the occurrence of Friday the 13th.
\end{abstract}

JEL-Code: C100, G100.

Keywords: Friday the 13th, GARCH, seasonality, emerging markets.

Benjamin R. Auer

University of Leipzig

Department of Finance

Grimmaische Straße 12

Germany - 04109 Leipzig

auer@wifa.uni-leipzig.de
Horst Rottmann

University of Applied Sciences

Amberg-Weiden

Hetzenrichter Weg 15

Germany - 92637 Weiden

h.rottmann@haw-aw.de 


\section{Introduction}

In the past decades, considerable research effort has been directed to the scientific analysis of calendar effects in stock market returns because their identification may allow the implementation of profitable investment strategies (see Lucey and Pardo, 2005; Ariss et al., 2011). Probably the most prominent of these effects are the Monday effect (see French, 1980; Pettengill, 2003; Keef et al., 2009), where Mondays' returns are much lower than other days of the week, the January effect (see Gultekin and Gultekin, 1983; Keim, 1983; Yao, 2012), where returns are much higher during the month of January than any in other month, and the turn-of-the-month effect (see Ariel, 1987; Kunkel et al., 2003), where returns at the end and at the beginning of a month tend to be higher than on other days. Recent research also considers Halloween effects (see Bouman and Jacobsen, 2002; Haggard and Witte, 2010) and even calendar phases exhibiting certain climate patterns (see Dowling and Lucey, 2005, 2008).

However, there is one effect that has received only limited attention - the superstitious Friday the 13th effect that attributes bad luck and thus low or negative returns to this specific calendar day. In their seminal article, published in the prestigious Journal of Finance, Kolb and Rodriguez (1987) found evidence in favour of this effect. Specifically, they showed that for the CRSP equal and value weighted indices, mean returns for Friday the 13th were significantly lower than for other Fridays. This result quickly prompted further research. In an examination of the S\&P 500 index, Dyl and Maberly (1988) concluded that the mean return for Friday the 13th is higher than for regular Fridays. However, the differences were not statistically significant. ${ }^{1}$ Chamberlain et al. (1991) found negative mean Friday the 13th returns but highlighted that after considering the turn-of-the-month effect, there is no evidence implying that Friday the 13th influences market returns. In an analysis of 18 countries, Agrawal and Tandon (1994) state that while the typical Friday the 13th return is positive it is statistically insignificant. However, nine of their 18 non-US indices reveal a lower mean return on Fridays the 13th compared to other Fridays. For the FTSE indices and FT-30 index, Mills and Coutts (1995) and Coutts (1999) observe a higher mean return on Friday the 13th compared to all other Fridays.

Lucey (2000, 2001), Patel (2009) and Botha (2013) point out that all Friday the 13th papers noted above have chosen to employ classic t-tests casting some doubt on the statistical reliability of their results because it is well-known that their use is critical in the presence of typical stock return characteristics (e. g. non-normality). Using a non-parametric Kruskal-Wallis test, Lucey $(2000,2001)$ finds that for 9 out of 19 developed stock markets, Friday the 13th mean returns are significantly greater than on regular Fridays. In only one country, South Africa, the mean return on Fridays the 13th is lower than on other Fridays. Patel (2009) employs the non-parametric Mann-Whitney test for the S\&P 500 and the NASDAQ index and finds that stock returns on Friday the 13th are not significantly lower than those of other Fridays. Applying the Kruskal-Wallis test, Botha (2013) also finds no evidence for the Friday the 13th effect in five African countries. Two other recent papers also use more sophisticated statistical methodology. Peltomäki and Peni (2010) apply a dummy-variable approach within standard autoregressive time series regression models for the S\&P 500 and the Dow Jones Industrial Average index to analyse a slightly modified definition of the phenomenon. They suggest that returns on trading days prior to (after) Friday the 13th should be lower (higher) than on average because of fear-related selling (relief-related buying) but find only limited and not robust evidence for this hypothesis. Keef and Khaled (2011) estimate a basic dummy- and GDP-augmented panel regression model for 62 international stock indices and come to the conclusion that the depressed

\footnotetext{
${ }^{1}$ Similarly, Maberly (1988) fails to find the effect for S\&P 500 futures contracts and argues that what has been documented is actually a "Friday the 13th bear market effect".
} 
Friday the 13th effect is present (absent) when the return on the prior day is negative (positive) and that the effect is independent of a country's GDP.

Our article contributes to this line of research in several ways. First, prior research mainly concentrates on the US and other developed stock markets. By focusing on the countries India, Indonesia, Malaysia, the Philippines, South Korea, Taiwan and Thailand, we test for the Friday the 13th effect in emerging Asian stock markets. Second, we are the first to not only analyse the impact of Friday the 13th on mean stock returns but also on stock market volatility. ${ }^{2}$ This is because the bad luck may also manifest itself in the form of higher volatility on that specific calendar day. Third, our empirical analysis is conducted on the basis of a more adequate statistical framework than used in previous studies. Specifically, we use a dummy-augmented GARCH specification that can capture important empirical features like leptokurtosis and volatility clustering observed in stock return data. ${ }^{3}$ Most studies dealing with calendar effects are usually carried out (with the usual linear regression model) under the assumption that error terms, and hence the returns, follow a normal distribution with constant variance (see de Jong et al., 1992). If these assumptions are violated, t-statistics will be biased towards finding calendar effects (see Connolly, 1989). The GARCH model applied in our study is capable of dealing with those problems and it makes the interpretation of t-statistics more robust. Furthermore, it is a natural choice for studying the direct effect of events on stock return volatility (see Choudhry, 2000).

The remainder of the article is organised as follows: Section 2 starts with a description of the econometric framework for testing the Friday the 13th effect. Section 3 presents the data set that is used in our study and provides a first descriptive analysis of Friday returns in emerging Asian stock markets. Section 4 contains the empirical analysis, including reported results, while Section 5 concludes.

\section{Methodology}

To statistically investigate the Friday the 13th effect, this article employs a simple state-of-the-art GARCH framework. Starting point is the well-known GARCH model proposed by Bollerslev (1986). We extend this standard model in two ways. First, in order to capture serial correlation in stock returns, we follow Bhattacharya et al. (2003) and add lagged returns to the mean equation. Second, to test for Friday effects in the returns and the volatility, we add two dummy-variables to both the mean and the variance equation. ${ }^{4}$ This leads to the following $\operatorname{GARCH}(\mathrm{p}, \mathrm{q})$ specification:

$$
\begin{gathered}
R_{t}=\alpha+\sum_{i=1}^{m} \beta_{i} R_{t-i}+\gamma_{1} F_{t}+\gamma_{2} F 13_{t}+\epsilon_{t} \\
\epsilon_{t} \mid \psi_{t-1} \sim N\left(0, h_{t}\right) \\
h_{t}=\delta+\sum_{j=1}^{p} \zeta_{j} \epsilon_{t-j}^{2}+\sum_{k=1}^{q} \eta_{k} h_{t-k}+\theta_{1} F_{t}+\theta_{2} F 13_{t}
\end{gathered}
$$

Here, the $\log$ return $R_{t}$ on a stock index at day $t$ is considered to be linearly related to its lagged values $R_{t-i}$, $i=1, \ldots, m$, two dummies $F_{t}$ and $F 13_{t}$, and an error term $\epsilon_{t}$. The dummy $F_{t}\left(F 13_{t}\right)$ takes the value 1 if the day $t$ is a Friday (Friday the 13th), and is 0 otherwise. $\epsilon_{t}$ depends on past information $\psi_{t-1}$ and is assumed

\footnotetext{
${ }^{2}$ There is only a limited number of studies that analyses the effects of any seasonality on volatility in Asian stock markets (see, for example, Ho and Cheung, 1994; Choudhry, 2000; Bhattacharya et al., 2003).

${ }^{3}$ Mandelbrot (1963) and Fama (1965) were among the first researchers that documented these typical stock return properties.

${ }^{4}$ Connolly (1989) and de Jong et al. (1992) highlight that by adding dummy-variables in the GARCH equations, effects of any periodic event may be tested on mean stock returns and volatility.
} 
to follow a conditional normal distribution. Thus, our model allows a conditionally heteroscedastic error distribution and, as a direct consequence, even captures fat-tail behavior (see Tsay, 2005, chpt. 3.5). As in the classic GARCH model, the conditional variance $h_{t}$ depends upon the squared residuals $\epsilon_{t-j}^{2}, j=1, \ldots, p$, of the process and lagged values $h_{t-k}, k=1, \ldots, q$, of the conditional variance. In our model, it is additionally related to two seasonal dummies.

In order to determine the size of $m, p$ and $q$ for each country, we employ a model selection procedure similar to Bollerslev (1988) and Choudhry (2000). The basic idea is to estimate models for different combinations of $m, p$ and $q$ and to evaluate their general descriptive validity. We start with a basic specification that assumes no serial correlation in returns $(m=0)$ but a typical GARCH process in the conditional variance $(p=1, q=1)$. Model parameters are estimated by the maximum likelihood procedure (see Davidson and MacKinnon, 2004; Greene, 2008, chpts. 13.6 and 19.3). To assess the adequacy of the model, we test the standardised residuals $\left(\epsilon_{t} / h_{t}^{0.5}\right)$ and the squared standardised residuals $\left(\epsilon_{t}^{2} / h_{t}\right)$ for serial correlation by means of the Ljung and Box (1978) test. Absence of serial correlation in the standardised (squared standardised) residuals implies the lack of need to encompass a higher order AR (GARCH) process in the mean (variance) equation. In case of serial correlation, we add AR and/or GARCH terms. We continue this procedure until we come up with a specification of (at conventional levels of $1 \%, 5 \%$ or $10 \%$ ) significant $\mathrm{AR}\left(\beta_{i}\right)$ and GARCH $\left(\zeta_{j}, \eta_{k}\right)$ parameters that is free of serial correlation. ${ }^{5}$

This preliminary specification is then tested for robustness with respect to two commonly used alternative GARCH models. This means that we add the term $\kappa h_{t}$ (or $\kappa h_{t}^{0.5}$ or $\kappa \ln \left(h_{t}\right)$ ) to the mean equation (1) to convert the model to a design of the GARCH-M type proposed by Engle et al. (1987). This modeling is reasonable since the return of a security may depend on its volatility. The significance of $\kappa$ then determines whether the extended model should be preferred to the initial one. Furthermore, to consider that shocks with opposite signs may impact volatility to a different extent, we also employ the T-GARCH model of Glosten et al. (1993) and Zakoian (1994). To this end, product terms are added to the variance equation (3). For example, in a model with $p=1$, we add $\lambda_{1} \epsilon_{t-1}^{2} D_{t-1}$, where $D_{t-1}$ is a dummy that takes the value 1 if $\epsilon_{t-1}<0$ and 0 if $\epsilon_{t-1} \geq 0$. This way a positive $\epsilon_{t-1}$ contributes $\zeta_{1} \epsilon_{t-1}^{2}$ to $h_{t}$, whereas a negative $\epsilon_{t-1}$ has larger impact $\left(\zeta_{1}+\lambda_{1}\right) \epsilon_{t-1}^{2}$ with $\lambda_{1}>0$. This mechanism creates a skewed error distribution. ${ }^{6}$

After finding the final adequate specification for each country, we can use the dummy variable coefficients to test for two Friday effects. First, empirical studies have documented that the average return on Fridays is abnormally high (see Jaffe and Westerfield, 1985; Keim and Stambaugh, 1984). This phenomenon can be analysed by the sign and significance of the coefficient $\gamma_{1}$ because a positive and significant $\gamma_{1}$ would indicate that returns on Fridays are significantly higher than on other weekdays. The coefficient $\theta_{1}$ allows us to answer the question whether the volatility on Fridays is different from other weekdays. Second, we can analyse the impact of Friday the 13th on returns and volatilities. A negative and significant $\gamma_{2}$ would indicate the classic Friday the 13th effect. That is, a lower return than on regular Fridays because of the occurrence of this specific calendar day. Friday the 13th may also show itself in the form of a positive and significant $\theta_{2}$ because this superstitious day may cause extraordinary market turbulences compared to other Fridays.

\footnotetext{
${ }^{5}$ In our application, a further increase of the AR or GARCH order does not significantly increase model fit. Also, the final specification outcome is not influenced if we either conduct our model selection procedure for the dummy-augmented model or a model without dummies that is extended afterwards.

${ }^{6}$ For a more detailed description of these GARCH models see Tsay (2005, chpts. 3.7 and 3.9) and Asteriou and Hall (2007, chpt. 14).
} 


\section{Data}

We utilise a data set consisting of the FTSE stock indices for India, Indonesia, Malaysia, the Philippines, South Korea, Taiwan and Thailand. Our country selection is motivated by the emerging markets study of Choudhry (2000). Unlike Agrawal and Tandon (1994) and Keef and Khaled (2011), we do not resort to national stock indices because these necessarily differ markedly in terms of composition method, coverage and technical detail, making results for different countries not strictly comparable. Instead, we follow Lucey (2001) and use FTSE indices that are designed for comparability and provide an ideal dataset for the investigation of the return phenomena across different emerging markets. The price indices are measured in local currency terms, which eliminates the danger of conflation of potential Friday the 13th effects in the stock and the foreign exchange market. ${ }^{7}$

The time period covered is July 1996 to August 2013. Daily $\log$ returns $R_{t}$ of a specific index for day $t$ are calculated as percentages in the conventional fashion using the formula $R_{t}=\left[\ln \left(I_{t}\right)-\ln \left(I_{t-1}\right)\right] \cdot 100$, where $I_{t}$ represents the closing value of the index on day $t$ (see Peiró, 1994). ${ }^{8}$ In terms of the theoretical sample size, this results in 4467 daily returns, 864 regular Fridays and 29 Fridays the 13th for each country. Because missing index values occur on days when a stock exchange is closed (because of predictable holidays or unexpected events), the actual sample size is typically lower (see Chamberlain et al., 1991) and differs from country to country. Antoniou et al. (1997) argue that in emerging market studies thin-trading or other kinds of non-trading days leading to unchanged prices (zero-returns) can negatively influence empirical results. Thus, we also exclude these days and finally come up with the sample sizes reported in Table $1 .{ }^{9}$

Table 1 analyses the basic characteristics of the return series for all seven countries. Along with calculating the mean, standard deviation, skewness and kurtosis, we test for normality of returns and for serial correlation in returns and squared returns by means of the Jarque and Bera (1987) and Ljung and Box (1978) tests. This testing is important for three reasons. First, strong kurtosis in returns indicates the adequacy of robust standard errors for inference (see Bollerslev and Wooldridge, 1992). Second, significant serial correlation in returns requires the inclusion of lagged returns as explanatory variables in GARCH mean equations (see Bhattacharya et al., 2003). Third, significant serial correlation in squared returns highlights time-varying volatility and thus the general appropriateness of GARCH modeling (see Joy, 2011).

The highest (lowest) mean return can be observed for the stock market index of Indonesia (Taiwan). Volatility takes its highest (lowest) value in South Korea (Malaysia). ${ }^{10}$ As far as the further distributional properties are concerned, the skewness in the data can be regarded as mild (see Lucey and Tully, 2006) but high kurtosis indicates strong deviations from normality. In fact, the null hypothesis of normally distributed returns is rejected at a $1 \%$ level for all countries. Furthermore, we find highly significant evidence of serial correlation in returns and squared returns for all countries. ${ }^{11}$

Table 2 reports descriptive statistics for the returns on regular Fridays and Fridays the 13th. As we can see, mean returns on Friday the 13th tend to be positive. Negative mean returns can only be observed for the Philippines and Thailand. Minimum and maximum returns on Friday the 13th are smaller (in absolute

\footnotetext{
${ }^{7}$ Lakonishok and Smidt (1988), Fishe et al. (1993) and Mills and Coutts (1995) note that conclusions of calendar effects are usually unaffected irrespective of whether dividend adjusted data is used or not.

${ }^{8}$ Unlike previous studies, we do not exclude non-Friday returns because this would not allow full information GARCH modeling and thus deliver no adequate description of the return generating processes.

${ }^{9}$ However, note that even without this correction our empirical results remain almost unchanged.

${ }^{10} \mathrm{~A}$ closer look at the first two moments reveals that recent evidence on a partially inverse risk-return relation (see Ang et al., 2006, 2009; Blitz and van Vliet, 2007; Baker et al., 2011) may also hold in an emerging market context.

${ }^{11}$ This is in line with earlier evidence that shows how returns from almost all capital markets are at least weakly related to their past values (see Campbell et al., 1997).
} 
values) than on regular Fridays. Only for the Philippines and Thailand, mean returns on Friday the 13th are lower than on regular Fridays. However, this observation is only of descriptive nature and does not allow conclusions regarding the (statistically significant) existence of a Friday the 13th effect.

\begin{tabular}{|c|c|c|c|c|c|c|c|c|}
\hline & \multirow[b]{2}{*}{ Obs. } & \multicolumn{6}{|c|}{ Returns } & \multirow{2}{*}{$\frac{\text { Squared returns }}{\mathrm{LB}(5) \text {-test }}$} \\
\hline & & Mean & Std.dev. & Skewness & Kurtosis & JB-test & LB(5)-test & \\
\hline India & 4219 & 0.034 & 1.660 & -0.241 & 8.985 & 6337.437 & 17.025 & 585.596 \\
\hline Indonesia & 4181 & 0.050 & 2.115 & -0.146 & 10.886 & 10847.977 & 100.604 & 660.881 \\
\hline Malaysia & 4208 & 0.012 & 1.470 & 0.606 & 49.244 & 375214.352 & 66.615 & 1870.883 \\
\hline Philippines & 4218 & 0.017 & 1.628 & 0.277 & 11.361 & 12338.596 & 102.068 & 254.397 \\
\hline South Korea & 4230 & 0.036 & 2.258 & 0.077 & 11.545 & 12873.502 & 45.035 & 335.504 \\
\hline Taiwan & 4183 & -0.004 & 1.645 & -0.003 & 5.401 & 1004.458 & 18.872 & 549.744 \\
\hline Thailand & 4173 & -0.003 & 2.232 & 0.725 & 13.684 & 20211.598 & 103.898 & 460.140 \\
\hline
\end{tabular}

For our sample covering the period from July 1996 to August 2013, this table reports the number of daily returns for each country (after exclusion of zero-returns) and the first four moments (mean, standard deviation, skewness, kurtosis) of the return distributions. The null hypothesis of normality is tested by means of the Jarque-Bera-test (JB-test). The null of no serial correlation in returns and squared returns up to order 5 is tested by means of the Ljung-Box-test (LB(5)-test). All given test statistics are significant at a $1 \%$ level.

Table 1: Characteristics of daily stock returns

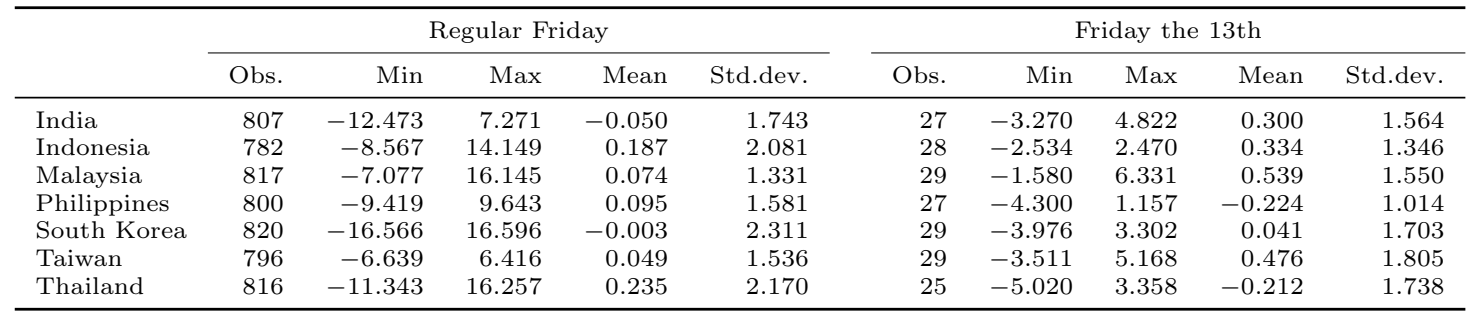

This table reports key statistics for two subsamples of the data characterised in Table 1. It shows the number of regular Fridays and Fridays the 13th for each country in our sample. Furthermore, it reports the minimum, maximum, mean and standard deviation of the returns for these specific calendar days.

Table 2: Descriptive statistics of Friday returns

Figure 1 gives a more detailed picture of the returns on Friday the 13th. It is immediately apparent that no systematic pattern emerges in the returns. This means that neither a strong negative nor a strong positive return tendency can be observed. However, for example, there is a light negative tendency for the Philippines. Even though one negative return observation strongly influences this tendency, it should not be excluded as an outliner because it represents no data error but a valid return of the population.

\section{Empirical results}

Table 3 presents the GARCH estimation results for our seven countries. Besides some statistics for diagnostic checking (log-likelihood value and Ljung-Box test results for the standardised and the squared standardised residuals), we report the estimates for the model parameters in the mean and variance equations. Their corresponding t-statistics are given in parentheses. ${ }^{12}$ As far as t-statistics are concerned, Tsay (2005, chpt. 3.5) argues that the tail behavior of GARCH models often remains too short (even with the standardised Student-t innovations suggested by Bollerslev, 1987). In this case, the GARCH parameter estimates will still be consistent, provided the mean and variance equations are correctly specified. However, the

\footnotetext{
${ }^{12}$ Due to space considerations we only report the outcomes of the final models. Detailed results from our specification search are available upon request.
} 

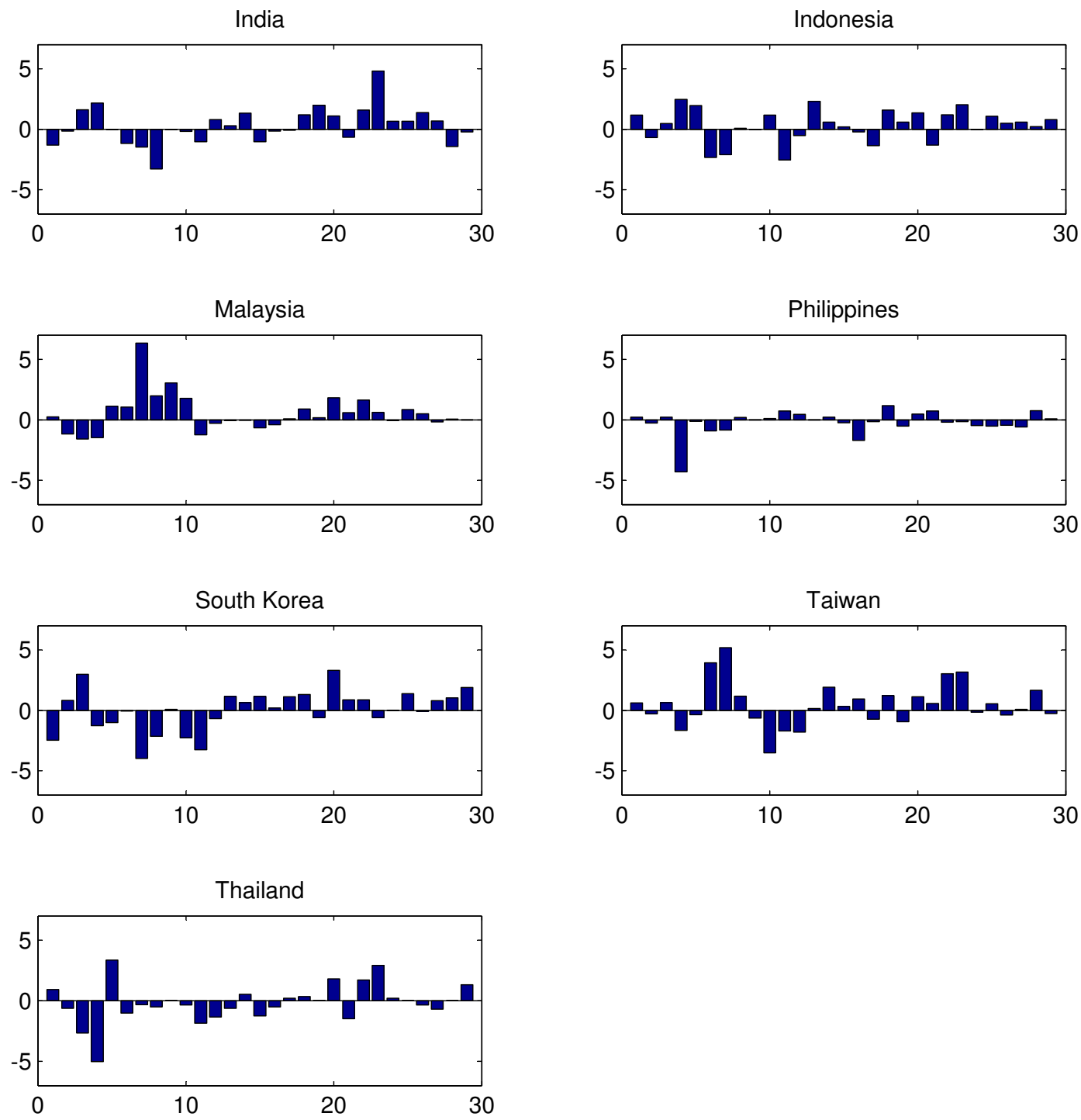

This figure shows the returns on Friday the 13 th in our sample of emerging Asian stock markets. Note that in order to allow a systematic comparison between countries, the bar plots also contain zero-returns resulting from closed exchanges.

Figure 1: Returns on Friday the 13th 
estimates of the covariance matrix will not be consistent resulting in incorrect standard errors and t-statistics. To avoid this problem that is very likely to occur in our high-kurtosis data (see Table 1), we compute the quasi-maximum likelihood covariances and standard errors proposed by Bollerslev and Wooldridge (1992) for obtaining our t-statistics.

Our model selection procedure finds that, with the exception of Taiwan, a GARCH $(1,1)$ specification is suitable for all our stock market returns. Our two alternative GARCH models (GARCH-M and T-GARCH) do either have no empirical support or do not provide notable improvement in fit. This undermines the findings of Bollerslev et al. (1992) and Hansen and Lunde (2005) that this simple heteroscedasticity design is sufficient for most financial time series. ${ }^{13}$

The Ljung-Box test statistics show that the models' standardised and squared standardised residuals are free of significant serial correlation at orders typically relevant for daily return data. This implies proper mean and variance specifications. While for Malaysia, South Korea, Taiwan and Thailand all estimates of the parameters $\beta_{i}$ are significant at conventional levels, we had to include lagged returns in the mean equations for India, Indonesia and the Philippines that are only close to a $10 \%$ significance in order to obtain models that pass the Ljung-Box test. ${ }^{14}$ Similarly, the variance equation for Taiwan contains one ARCH coefficient $\zeta_{j}$ with a t-value of 1.44, while all other models show only highly significant GARCH effects $\zeta_{j}$ and $\eta_{k}$. All estimated GARCH processes show a high degree of persistence. That is, the sums of $\zeta_{j}$ and $\eta_{k}$ are all close to one.

Concentrating on the dummy variables in the mean equations first, we find a significant and positive coefficient $\gamma_{1}$ for Indonesia, Malaysia, the Philippines and Thailand. This result implies that in these stock markets mean returns on Fridays are significantly higher than on other weekdays and thus supports the previous findings of Keim and Stambaugh (1984) and Jaffe and Westerfield (1985) for developed stock markets. Inference for the coefficient $\gamma_{2}$ indicates a Friday the 13th effect only for the Philippines. Here, returns on Friday the 13th are significantly lower than on regular Fridays. We can also observe this negative impact on mean returns for Thailand. However, for this country, it is not statistically significant. ${ }^{15}$ For South Korea, we can observe a significant inverse Friday the 13th effect. Here, returns on Friday the 13th are significantly higher than on regular Fridays. For all other countries, i. e. the majority of countries, we cannot detect any significant effects.

Turning to the dummies in the variance equations, we can see that the coefficient $\theta_{1}$ is insignificant for all countries implying that volatility on Fridays does not significantly differ from other weekdays' volatility. Results for $\theta_{2}$ show that Friday the 13th significantly influences stock market volatility only in Indonesia and the Philippines. However, the sign is different from our expectation. Friday the 13th does not lead to increased but reduced volatility in comparison to regular Fridays. For all other countries, we find no significant effects.

Before stating a final conclusion on the Friday the 13th effect in emerging Asian stock markets, an important result from the literature has to be taken into consideration. Chamberlain et al. (1991) documents that Fridays at the turn-of-the-month ${ }^{16}$ exhibit an enhanced turn-of-the-month effect. This implies that an

\footnotetext{
${ }^{13}$ Similar indications can be found in the emerging stock market study of Choudhry (2000), the precious metal research of Lucey and Tully (2006) and the diamond, currency and developed stock market analysis of Auer and Schuhmacher (2013) and Auer (2013).

${ }^{14}$ Note that dropping the variables with t-values between 1.1 and 1.6 does not influence our conclusions regarding the Friday the 13th effect in our selection of stock markets.

${ }^{15}$ Thus our GARCH models nicely resemble the negative mean Friday the 13th returns for the Philippines and Thailand documented in Table 2 .

${ }^{16}$ In the literature, the turn of the month is defined as the last calendar day of the prior month and the first three calendar days of the new month (see, for example, Lakonishok and Smidt, 1988; Kunkel et al., 2003; McConnell and Xu, 2008).
} 


\begin{tabular}{|c|c|c|c|c|c|c|c|}
\hline & India & Indonesia & Malaysia & Philippines & South Korea & Taiwan & Thailand \\
\hline \multicolumn{8}{|l|}{ Mean equation } \\
\hline$\alpha$ & $\begin{array}{c}0.097^{a} \\
(4.336)\end{array}$ & $\begin{array}{c}0.063^{b} \\
(2.444)\end{array}$ & $\begin{array}{c}0.033^{a} \\
(2.825)\end{array}$ & $\begin{array}{c}0.009 \\
(0.425)\end{array}$ & $\begin{array}{c}0.085^{a} \\
(3.363)\end{array}$ & $\begin{array}{c}0.030 \\
(1.323)\end{array}$ & $\begin{array}{c}0.031 \\
(1.082)\end{array}$ \\
\hline$\beta_{1}$ & $\begin{array}{r}0.075^{a} \\
(4.375)\end{array}$ & $\begin{array}{l}0.131^{a} \\
(7.227)\end{array}$ & $\begin{array}{r}0.152^{a} \\
(8.401)\end{array}$ & $\begin{array}{r}0.130^{a} \\
(7.161)\end{array}$ & $\begin{array}{r}0.037^{b} \\
(2.200)\end{array}$ & $\begin{array}{r}0.043^{a} \\
(2.607)\end{array}$ & $\begin{array}{r}0.110^{a} \\
(5.679)\end{array}$ \\
\hline$\beta_{2}$ & - & $\begin{array}{l}-0.034^{c} \\
(-1.901)\end{array}$ & - & - & - & - & $\begin{array}{r}0.035^{c} \\
(1.812)\end{array}$ \\
\hline$\beta_{3}$ & - & $\begin{array}{c}-0.028 \\
(-1.538)\end{array}$ & - & $\begin{array}{l}-0.047^{a} \\
(-2.650)\end{array}$ & - & - & $\begin{array}{l}-0.035^{b} \\
(-1.992)\end{array}$ \\
\hline$\beta_{4}$ & $\begin{array}{c}0.022 \\
(1.277)\end{array}$ & - & - & $\begin{array}{c}0.021 \\
(1.157)\end{array}$ & $\begin{array}{l}-0.050^{a} \\
(-2.855)\end{array}$ & $\begin{array}{l}-0.032^{b} \\
(-1.989)\end{array}$ & - \\
\hline$\beta_{5}$ & $\begin{array}{l}-0.030^{c} \\
(-1.811)\end{array}$ & - & - & $\begin{array}{l}-0.047^{a} \\
(-2.796)\end{array}$ & $\begin{array}{r}-0.050^{b} \\
(-2.418)\end{array}$ & - & - \\
\hline$\gamma_{1}$ & $\begin{array}{l}-0.040 \\
(-0.794)\end{array}$ & $\begin{array}{r}0.182^{a} \\
(2.827)\end{array}$ & $\begin{array}{r}0.052^{c} \\
(1.666)\end{array}$ & $\begin{array}{r}0.152^{b} \\
(2.231)\end{array}$ & $\begin{array}{l}-0.068 \\
(-1.154)\end{array}$ & $\begin{array}{c}0.048 \\
(0.944)\end{array}$ & $\begin{array}{r}0.266^{a} \\
(4.004)\end{array}$ \\
\hline$\gamma_{2}$ & $\begin{array}{c}0.193 \\
(0.898)\end{array}$ & $\begin{array}{c}0.281 \\
(1.283)\end{array}$ & $\begin{array}{c}0.096 \\
(0.688)\end{array}$ & $\begin{array}{l}-0.331^{b} \\
(-2.003)\end{array}$ & $\begin{array}{r}0.527^{c} \\
(1.854)\end{array}$ & $\begin{array}{c}0.285 \\
(1.190)\end{array}$ & $\begin{array}{l}-0.289 \\
(-1.047)\end{array}$ \\
\hline $\begin{array}{l}\text { Variance equation } \\
\delta\end{array}$ & $\begin{array}{c}0.031 \\
(1.101)\end{array}$ & $\begin{array}{c}0.044 \\
(1.419)\end{array}$ & $\begin{array}{c}0.003 \\
(0.304)\end{array}$ & $\begin{array}{r}0.184^{a} \\
(3.135)\end{array}$ & $\begin{array}{c}0.024 \\
(0.884)\end{array}$ & $\begin{array}{l}-0.010 \\
(-0.456)\end{array}$ & $\begin{array}{c}0.026 \\
(0.582)\end{array}$ \\
\hline$\zeta_{1}$ & $\begin{array}{r}0.118^{a} \\
(8.178)\end{array}$ & $\begin{array}{r}0.113^{a} \\
(8.122)\end{array}$ & $\begin{array}{r}0.137^{a} \\
(8.386)\end{array}$ & $\begin{array}{r}0.157^{a} \\
(7.931)\end{array}$ & $\begin{array}{r}0.065^{a} \\
(5.370)\end{array}$ & $\begin{array}{c}0.030 \\
(1.443)\end{array}$ & $\begin{array}{r}0.100^{a} \\
(7.053)\end{array}$ \\
\hline$\zeta_{2}$ & - & - & - & - & - & $\begin{array}{r}0.043^{c} \\
(1.951)\end{array}$ & - \\
\hline$\eta_{1}$ & $\begin{array}{r}0.868^{a} \\
(60.803)\end{array}$ & $\begin{array}{r}0.879^{a} \\
(64.771)\end{array}$ & $\begin{array}{r}0.865^{a} \\
(64.468)\end{array}$ & $\begin{array}{r}0.806^{a} \\
(41.408)\end{array}$ & $\begin{array}{r}0.938^{a} \\
(81.276)\end{array}$ & $\begin{array}{r}0.919^{a} \\
(88.929)\end{array}$ & $\begin{array}{r}0.886^{a} \\
(60.860)\end{array}$ \\
\hline$\theta_{1}$ & $\begin{array}{c}0.117 \\
(0.894)\end{array}$ & $\begin{array}{c}0.098 \\
(0.633)\end{array}$ & $\begin{array}{c}0.050 \\
(1.029)\end{array}$ & $\begin{array}{l}-0.306 \\
(-1.419)\end{array}$ & $\begin{array}{l}-0.070 \\
(-0.495)\end{array}$ & $\begin{array}{c}0.170 \\
(1.468)\end{array}$ & $\begin{array}{c}0.276 \\
(0.675)\end{array}$ \\
\hline$\theta_{2}$ & $\begin{array}{l}-0.329 \\
(-1.621)\end{array}$ & $\begin{array}{l}-0.385^{c} \\
(-1.804)\end{array}$ & $\begin{array}{c}-0.054 \\
(-0.951)\end{array}$ & $\begin{array}{l}-0.545^{a} \\
(-3.437)\end{array}$ & $\begin{array}{l}-0.025 \\
(-0.103)\end{array}$ & $\begin{array}{c}0.016 \\
(0.068)\end{array}$ & $\begin{array}{l}-0.470 \\
(-0.756)\end{array}$ \\
\hline \multicolumn{8}{|l|}{ Diagnostics } \\
\hline $\mathrm{LL} \cdot 10^{-3}$ & -7.528 & -8.303 & -5.767 & -7.515 & -8.547 & -7.550 & -8.393 \\
\hline $\mathrm{LB}(5)$ for $\epsilon_{t} / h_{t}^{0.5}$ & 7.623 & 4.875 & 9.063 & 8.738 & 5.090 & 2.083 & 3.253 \\
\hline $\mathrm{LB}(10)$ for $\epsilon_{t} / h_{t}^{0.5}$ & 13.789 & 13.352 & 14.331 & 14.281 & 12.405 & 6.250 & 14.601 \\
\hline $\mathrm{LB}(5)$ for $\epsilon_{t}^{2} / h_{t}$ & 2.287 & 4.905 & 3.066 & 1.520 & 3.592 & 7.954 & 1.117 \\
\hline $\mathrm{LB}(10)$ for $\epsilon_{t}^{2} / h_{t}$ & 7.902 & 10.127 & 8.953 & 2.837 & 5.940 & 10.122 & 1.568 \\
\hline
\end{tabular}

This table shows the maximum likelihood estimation results for our GARCH specification described in Section 2. Robust BollerslevWooldridge t-statistics are given in parentheses. LL is the $\log$-likelihood value. LB $(x)$ represents the Ljung-Box test statistic for serial correlation up to order $\mathrm{x}$. a, b and c imply significance at $1 \%, 5 \%$ and $10 \%$ levels, respectively.

Table 3: GARCH model estimation results

empirical analysis may be biased towards finding a significant Friday the 13th effect since the returns of the regular Fridays are enhanced by the turn-of-the-month effect. However, no bias exists if the turn-ofthe-month effect has the same influence on the returns of all days. To counteract this potential bias for our Philippines model and as a robustness check, we followed Keef and Khaled (2011) and incorporated a dummy-variable for the turn of the month in our model. As Fridays may also be affected by the January effect, we also included a suitable January-dummy. However, in both cases, our Friday the 13th dummy remained negative and significant.

\section{Conclusion}

Recent research directs increased interest towards the Friday the 13th effect of Kolb and Rodriguez (1987) because evidence on this phenomenon could indicate that stock markets are impacted by human superstition. That is, investors may tend to sell stocks on that specific calendar day because of the perception that it is attributed to bad luck. As a consequence, they would cause the negative market impact of which they are afraid of, themselves.

Most previous studies find that Friday the 13th returns are not lower, but may even be higher than the other Friday returns. Furthermore, some articles show that a Friday the 13th effect may only exist under certain conditions (see Section 1). As existing studies mainly cover developed stock markets and use 
statistical methodologies that do not capture important characteristics of daily stock returns, our article extends the literature by examining the phenomenon in an emerging Asian stock market context and by using a state-of-the-art GARCH methodology. Even though we find a significant Friday the 13th effect in the stock returns of the Philippines, we cannot conclude that the phenomenon is robust across countries. Five of seven countries show no significant effects at all. For one country, we can even observe a significant inverse Friday the 13th effect. In a further analysis of the impact of Friday the 13th on stock market volatility, we find that contrary to intuition Friday the 13th is accompanied by reduced volatility. However, this reduction is only significant in two of seven cases.

As evidence on this superstitious effect is rather disappointing in an emerging Asian stock market context, two directions may be suggested for future research. First, one might leave the boundaries of time series models that concentrate on explaining the behaviour of a series based on its own past. The mean equations of the model presented in our article may be extended by including factors of systematic risk that have been identified in the literature. For example, one could construct the well-known factors of Fama and French (1993) and Carhart (1997) for the emerging Asian markets in our sample. Second, researchers may direct their attention away from stock markets and towards markets where research on calendar effects is extremely thin. One example for such markets is the precious metals market. Even though scientists have already discovered many important properties of the investment returns on those metals (see, for example, Lucey, 2011), research on seasonalities has just begun (see Lucey and Tully, 2006; Lucey, 2010). So far there exists no study on the Friday the 13th effect in those markets.

\section{References}

Agrawal, A., Tandon, K., 1994. Anomalies or Illusions? Evidence from Stock Markets in Eighteen Countries. Journal of International Money and Finance 13 (1), 83-106.

Ang, A., Hodrick, R., Xing, Y., Zhang, X., 2006. The Cross-Section of Volatility and Expected Returns. Journal of Finance 61 (1), 259-299.

Ang, A., Hodrick, R., Xing, Y., Zhang, X., 2009. High Idiosyncratic Volatility and Low Returns: International and Further U.S. Evidence. Journal of Financial Economics 91 (1), 1-23.

Antoniou, A., Ergul, N., Holmes, P., 1997. Market Efficiency, Thin Trading and Non-Linear Behaviour: Evidence from an Emerging Market. European Financial Management 3 (2), 175-190.

Ariel, R., 1987. A Monthly Effect in Stock Returns. Journal of Financial Economics 18 (1), 161-174.

Ariss, R., Rezvanian, R., Mehdian, S., 2011. Calendar Anomalies in the Gulf Cooperation Council Stock Markets. Emerging Markets Review 12 (3), 293-307.

Asteriou, D., Hall, S., 2007. Applied Econometrics - A Modern Approach, Revised Edition. Palgrave Macmillan, New York.

Auer, B., 2013. Could Diamonds Become an Investor's Best Friend? Review of Managerial Science, forthcoming.

Auer, B., Schuhmacher, F., 2013. Diamonds - A Precious New Asset? International Review of Financial Analysis 28, $182-189$.

Baker, M., Bradley, B., Wurgler, J., 2011. Benchmarks as Limits to Arbitrage: Understanding the Low-Volatility Anomaly. Financial Analysts Journal 67 (1), 40-54.

Bhattacharya, K., Sarkar, N., Mukhopadhyay, D., 2003. Stability of the Day of the Week Effect in Return and Volatility at the Indian Capital Market: A GARCH Approach with Proper Mean Specification. Applied Financial Economics 13 (8), 553-563.

Blitz, D., van Vliet, P., 2007. The Volatility Effect. Journal of Portfolio Management 34 (1), 102-113.

Bollerslev, T., 1986. Generalized Autoregressive Conditional Heteroskedasticity. Journal of Econometrics 31 (3), $307-327$.

Bollerslev, T., 1987. A Conditional Heteroscedastic Time Series Model for Speculative Prices and Rates of Return. Review of Economics and Statistics 69 (3), 542-547.

Bollerslev, T., 1988. On the Correlation Structure for the Generalized Autoregressive Conditional Heteroscedastic Process. Journal of Time Series Analysis 9 (2), 121-131.

Bollerslev, T., Chou, R., Kroner, K., 1992. ARCH-Modeling in Finance: A Review of the Theory and Empirical Evidence. Journal of Econometrics 52 (1-2), 5-59.

Bollerslev, T., Wooldridge, J., 1992. Quasi-Maximum Likelihood Estimation and Inference in Dynamic Models with TimeVarying Covariances. Econometric Reviews 11 (2), 143-172. 
Botha, F., 2013. Stock Returns and Friday the 13th Effect in Five African Countries. African Review of Economics and Finance $4(2), 247-253$.

Bouman, S., Jacobsen, B., 2002. The Halloween Indicator, "Sell in May and Go Away": Another Puzzle. American Economic Review 92 (5), 1618-1635.

Campbell, J., Lo, A., MacKinlay, A., 1997. The Econometrics of Financial Markets. Princeton University Press, Princeton.

Carhart, M., 1997. On Persistence in Mutual Fund Performance. Journal of Finance 52 (1), 57-82.

Chamberlain, T., Cheung, C., Kwan, C., 1991. The Friday the Thirteenth Effect: Myth or Reality? Quarterly Journal of Business and Economics 30 (2), 111-117.

Choudhry, T., 2000. Day of the Week Effect in Emerging Asian Stock Markets: Evidence from the GARCH Model. Applied Financial Economics 10 (3), 235-242.

Connolly, R., 1989. An Examination of the Robustness of the Weekend Effect. Journal of Financial and Quantitative Analysis $24(2), 133-169$.

Coutts, J., 1999. Friday the Thirteenth and The Financial Times Industrial Ordinary Shares Index 1935-94. Applied Economics Letters 6 (1), 35-37.

Davidson, R., MacKinnon, J., 2004. Econometric Theory and Methods. Oxford University Press, Oxford.

de Jong, F., Kemna, A., Kloek, T., 1992. A Contribution to Event Study Methodology with an Application to the Dutch Stock Market. Journal of Banking and Finance 16 (1), 11-36.

Dowling, M., Lucey, B., 2005. Weather, Biorhythms, Beliefs and Stock Returns - Some Preliminary Irish Evidence. International Review of Financial Analysis 14 (3), 337-355.

Dowling, M., Lucey, B., 2008. Robust Global Mood Influences in Equity Pricing. Journal of Multinational Financial Management 18 (2), 145-164.

Dyl, E., Maberly, E., 1988. The Anomaly that isn't there: A Comment on Friday the Thirteenth. Journal of Finance 43 (5), $1285-1286$.

Engle, R., Lilien, D., Robins, R., 1987. Estimating Time-Varying Risk Premia in the Term Structure: The ARCH-M Model. Econometrica 55 (2), 391-407.

Fama, E., 1965. The Behaviour of Stock Market Prices. Journal of Business 38 (1), 34-105.

Fama, E., French, K., 1993. Common Risk Factors in the Returns on Stocks and Bonds. Journal of Financial Economics 33 (1), $3-56$.

Fishe, R., Gosnell, T., Lasser, D., 1993. Good News, Bad News, Volume and the Monday Effect. Journal of Business Finance and Accounting 20 (6), 881-892.

French, K., 1980. Stock Returns and the Weekend Effect. Journal of Financial Economics 8 (1), 55-69.

Glosten, L., Jagannathan, R., Runkle, D., 1993. On the Relation Between the Expected Value and the Volatility of Nominal Excess Return on Stocks. Journal of Finance 48 (5), 1779-1801.

Greene, W., 2008. Econometric Analysis, 6th Edition. Prentice Hall, New York.

Gultekin, M., Gultekin, N., 1983. Stock Market Seasonality: International Evidence. Journal of Financial Economics 12 (4), 469-481.

Haggard, K., Witte, H., 2010. The Halloween Effect: Trick or Treat? International Review of Financial Analysis 19 (5), 379-387.

Hansen, P., Lunde, A., 2005. A Forecast Comparison of Volatility Models: Does Anything Beat a GARCH(1,1)? Journal of Applied Econometrics 20 (7), 873-889.

Ho, R., Cheung, Y., 1994. Seasonal Pattern In Volatility in Asian Stock Markets. Applied Financial Economics 4 (1), 61-67.

Jaffe, J., Westerfield, R., 1985. The Weekend Effect in Common Stock Returns: The International Evidence. Journal of Finance $40(2), 433-454$.

Jarque, C., Bera, A., 1987. A Test for Normality of Observations and Regression Residuals. International Statistical Review 55 (2), 163-172.

Joy, M., 2011. Gold and the US-Dollar: Hedge or Haven? Finance Research Letters 8 (3), 120-131.

Keef, S., Khaled, M., 2011. The Friday the Thirteenth Effect in Stock Prices: International Evidence Using Panel Data, Working Paper No 17/2011, University of Wellington.

Keef, S., Khaled, M., Zhu, H., 2009. The Danamics of the Monday Effect in International Stock Indices. International Review of Financial Analysis 18 (3), 125-133.

Keim, D., 1983. Size-Related Anomalies and Stock Return Seasonality: Further Empirical Evidence. Journal of Financial Economics 12 (1), 13-32.

Keim, D., Stambaugh, R., 1984. A Further Investigation of the Weekend Effect in Stock Returns. Journal of Finance 39 (3), 819-835.

Kolb, R., Rodriguez, R., 1987. Friday the Thirteenth Part VII: A Note. Journal of Finance 42 (5), 1385-1387.

Kunkel, R., Compton, W., Beyer, S., 2003. The Turn-of-the-Month Effect Still Lives: The International Evidence. International 
Review of Financial Analysis 12 (2), 207-221.

Lakonishok, J., Smidt, S., 1988. Are Seasonal Anomalies Real? A Ninety-Year Perspective. Review of Financial Studies 1 (4), $403-425$.

Ljung, G., Box, G., 1978. On a Measure of Lack of Fit in Time Series Models. Biometrika 65 (2), 297-303.

Lucey, B., 2000. Friday the 13th and the Philosophical Basis of Financial Economics. Journal of Economics and Finance 24 (3), 294-301.

Lucey, B., 2001. Friday the 13th: International Evidence. Applied Economics Letters 8 (9), 577-579.

Lucey, B., 2010. Lunar Seasonality in Precious Metals Returns? Applied Economics Letters 17 (9), 835-838.

Lucey, B., 2011. What do academics (think) they know about gold? Alchemist 62, 12-14.

Lucey, B., Pardo, A., 2005. Why Investors Should Not Be Cautious About the Academic Approach to Testing for Stock Market Anomalies. Applied Financial Economics 15 (3), 165-171.

Lucey, B., Tully, E., 2006. Seasonality, Risk and Return in Daily COMEX Gold and Silver Data 1982-2002. Applied Financial Economics 16 (4), 319-333.

Maberly, E., 1988. The Other Friday "Bull" Effect: A Chance Occurrence or the Harbinger of Yet Another Puzzling Anomaly? A Note! Journal of Futures Markets 8 (6), 723-724.

Mandelbrot, B., 1963. The Variation of Certain Speculative Prices. Journal of Business 36 (4), 394-419.

McConnell, J., Xu, W., 2008. Equity Returns at the Turn of the Month. Financial Analysts Journal 64 (2), 49-64.

Mills, T., Coutts, J., 1995. Calendar Effects in the London Stock Exchange FT-SE Indices. European Journal of Finance 1 (1), 79-93.

Patel, J., 2009. Recent Evidence On Friday the Thirteenth Effect in U.S. Stock Returns. Journal of Business and Economics Research 7 (3), 55-58.

Peiró, A., 1994. Daily Seasonality in Stock Returns - Further International Evidence. Economics Letters 45 (2), $227-232$.

Peltomäki, J., Peni, E., 2010. Friday the Thirteenth and the Stock Market, Unpublished Manuscript, University of Vaasa.

Pettengill, G., 2003. A Survey of the Monday Effect Literature. Quarterly Journal of Business and Economics 42 (3/4), 3-27.

Tsay, R., 2005. Analysis of Financial Time Series, 2nd Edition. Wiley \& Sons, Hoboken.

Yao, Y., 2012. Momentum, Contrarian, and the January Seasonality. Journal of Banking and Finance 36 (10), $2757-2769$.

Zakoian, J., 1994. Threshold Heteroscedastic Models. Journal of Economic Dynamics and Control 18 (5), 931-955. 